\title{
The Impact of the Family and Health Workers on Psychosocial Adaptation and the Process of Treatment of Oncological Patients
}

\author{
Olivera Kalajdžić ${ }^{*}$, Jelena Pavlović \\ ${ }^{1}$ Department of Psychology, Faculty of Medicine in Foča, University of East Sarajevo, The Republic of Srpska, Bosnia and \\ Herzegovina; ' Department of Nursing, Faculty of Medicine in Foca, University of East Sarajevo, The Republic of Srpska, \\ Bosnia and Herzegovina
}

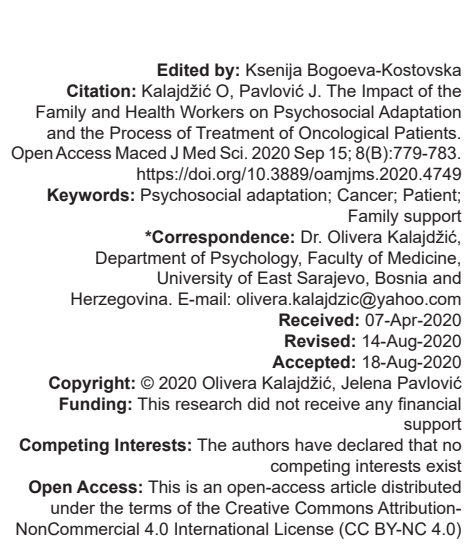

\section{Abstract}

BACKGROUND: Psychological support for patients and their families is of great importance at times when they go through shock, stress, and fear at moments when confronted with diagnosis and treatment.

AIM: Aim to this study was to examine the influence of family attitudes on psychosocial adaptation and the effect of treatment of patients with malignancies to preserve the integrity of the diseased person in Bosnia and Herzegovina.

METHODS: The cross-sectional study included 100 patients who were hospitalized at Foca University Hospital, Department of Oncology between September 2019 and December 2019. The survey used a sociodemographic questionnaire as well as a standardized questionnaire to evaluate communication with patients with malignant diseases for the patient and family (CCAT-PF)

RESULTS: More than half of the respondents $(69 \%)$ accepted the malignancy. When it comes to communication between health-care professionals and patients, $51 \%$ are satisfied with the communication and $49 \%$ are not satisfied. Most respondents $(62 \%)$ hesitate to talk about side effects during treatment with health-care professionals, with a statistically significant difference observed between male and female respondents $\left(\chi^{2}=6,014 ; p=0.014\right)$.

CONCLUSION: The time devoted to the subjects by the physicians as well as the willingness to listen to the patient is important aspects that influence the adaptation of the disease as well as the treatment.

\section{Introduction}

The first reaction in patients when they find out they are suffering from malignancies is fear. We will help such patients by showing them compassion [1]. Psychological assistance and support include listening to the patient's problems and needs, supporting and encouraging the patient, as well as looking at problems and possible solutions. In providing support, family and friends are of great importance. However, professional psychological assistance to patients with malignant disease should be provided by professionals with years of experience in providing emotional, psychological, and psychotherapy assistance in the stages of crisis and loss of emotional strength [2]. To create emotional support, it is necessary to communicate with family members. Oncology nurses need to have certain qualities (moral qualities, expertise, high level of empathy for the patient, and family members) that are the key to efficiency in the care of oncology patients [3]. However, it is important to coordinate the work of the whole team because it is a way of verbalizing fears, reducing the fear of death and improving the quality of life. Psychological support for patients and their families is of great importance at times when they go through shock, stress, and fear at moments when confronted with diagnosis and treatment [4], [5]. No local study in our country has examined the unmet needs of cancer patients; it becomes necessary to assess the magnitude and factors associated with unmet needs and psychosocial support. Proper assessment helps to identify patients with higher levels of need quickly and early so that the necessary interventions that can improve the psychosocial well-being of the patients can be targeted very early. In addition, we also aim to this study was to examine the influence of family attitudes on psychosocial adaptation and the effect of treatment of patients with malignancies to preserve the integrity of the diseased person in Bosnia and Herzegovina.

\section{Methods}

\section{Participants}

The cross-sectional study included 100 patients who were hospitalized at Foca University Hospital, Department of Oncology between September and December 2019. At the beginning of the study, all 
subjects were informed of the research goals, and their informed consent was sought. The criteria for inclusion of the respondents in the research are the diagnosis of malignancy and the age of the respondents over 18 years.

\section{Instruments}

The survey used a sociodemographic questionnaire as well as a standardized questionnaire to evaluate communication with patients with malignant diseases for the patient and family (CCAT-PF) [6]. The sociodemographic questionnaire is specifically designed for this type of research. It includes data from the respondents pertaining to: Gender, years of life, marital status, place of residence, working status, and economic status assessment. The second part deals with data on the characteristics of behaviors and habits related to health as well as social functioning. Three questions cover respondents' perceptions of communication with health-care professionals in relation to the manner in which information about the disease was provided and which will be compared with the answers given in other questionnaires. The standardized questionnaire was used in the paper as a tool for evaluating communication with patients with CCAT-PF. The questionnaire includes 18 items that state positive or negative answers to the stated claims. The CCAT-PF questionnaire is a valid reliable tool for obtaining information on patienthealth relationships as well as relationships in support of the family for the sick. As it consists of two parts, individual questionnaires can be used. The purpose of the survey is to give the respondents precise answers about their preferences, values, and experiences in the implementation of treatment, but with an emphasis on how the family that is also participating in the treatment fits into this process.

\section{Statistical analysis}

The paper uses the SPSS software tool (Statistical Package for the Social Sciences) to produce spreadsheets and descriptive statistics. Descriptive statistics were used. A Chi-square test was used to test the hypothesis in the paper, and a $5 \%$ probability of deviation was used. Pearson's correlation coefficient was used to determine collation. The Pearson correlation coefficient value ranges from +1 (perfect positive correlation) to -1 (perfect negative correlation). The obtained research results are presented in tabular form.

\section{Results}

The study included 100 subjects with malignancies. Among the respondents were $12 \%$ men and $88 \%$ women. The majority of respondents belonged to the age group over 50 (88\%). All respondents were married $(100 \%)$, and in $61 \%$ of respondents, the malignant disease was already present in the family. More than half of the respondents (69\%) accepted the malignancy. When it comes to communication between health-care professionals and patients, $51 \%$ are satisfied with the communication and $49 \%$ are not satisfied (Table 1).

Table 1: Demographic characteristics of study participants

\begin{tabular}{ll}
\hline Variables & $\mathrm{n}=100(\%)$ \\
\hline Gender & 12 \\
Male & 88 \\
Female & 15 \\
Ages (years) & 15 \\
$33-50$ & 85 \\
$>50$ & 100 \\
Marital status & 0 \\
Yes & \\
No & 61 \\
Positive history & 39 \\
Yes & \\
No & 69 \\
Acceptance of the disease & 31 \\
Yes & \\
No & 51 \\
Communication & 49 \\
Satisfied & \\
Unhappy & \\
\hline
\end{tabular}

There is no statistically significant difference when it comes to the role of the respondent's family in treatment decisions. In Table 2, the results show that in $69 \%$ of the respondents, families have a large role to play in decisions, and in older respondents. Most respondents $(62 \%)$ hesitate to talk about side effects during treatment with health-care professionals, with a statistically significant difference observed between male and female respondents $\left(\chi^{2}=6,014 ; p=0.014\right)$, with a significantly higher number of women who hesitate talk about side effects during treatment with their doctor or nurse versus men $(54 \%$ ) (Table 2). Most respondents $>51$ years of age $(63 \%)$ are willing to try any treatment that medicine finds. Older respondents (49\%) of the female sex (48\%) were of the opinion that side effects did not matter if they were to be cured. No statistically significant difference was observed between subjects of different age and gender (Table 3). Table 4 shows that $89 \%$ of respondents believe that the decision regarding treatment is independent of the family's positive opinion of the physician. It is important for most respondents $(96 \%)$ that they receive treatment information from multiple sources, not just their physician. No statistically significant difference was observed between respondents of different sex and age (Table 4). Pearson's correlation coefficient ( $r$ ) showed

Table 2. Family involvement in treatment decisions by age and gender of respondents

\begin{tabular}{|c|c|c|c|c|c|}
\hline \multirow[t]{2}{*}{ CCAT-PF } & \multirow[t]{2}{*}{ Variables } & \multicolumn{2}{|c|}{$\mathrm{n}=100(\%)$} & \multirow[t]{2}{*}{$\chi^{2}$} & \multirow[t]{2}{*}{$\mathrm{p}$} \\
\hline & & Yes & No & & \\
\hline The role of the family in & Years & & & 0.417 & 0.511 \\
\hline \multirow{5}{*}{ treatment decisions } & $33-50$ & 12 & 0 & & \\
\hline & $51-75$ & 69 & 19 & & \\
\hline & Gender & & & 0.929 & 0.325 \\
\hline & Men & 9 & 1 & & \\
\hline & Women & 74 & 16 & & \\
\hline \multirow{6}{*}{$\begin{array}{l}\text { I hesitate to talk about side } \\
\text { effects or occurrences during } \\
\text { treatment with my doctor }\end{array}$} & Years & & & 1.768 & 0.184 \\
\hline & $33-50$ & 7 & 3 & & \\
\hline & $51-75$ & 54 & 36 & & \\
\hline & Gender & & & 6.014 & 0.014 \\
\hline & Men & 8 & 2 & & \\
\hline & Women & 54 & 36 & & \\
\hline
\end{tabular}


Table 3: Types and acceptance of treatment by age and gender of subjects

\begin{tabular}{|c|c|c|c|c|c|}
\hline \multirow[t]{2}{*}{ CCAT-PF } & \multirow[t]{2}{*}{ Variables } & \multicolumn{2}{|c|}{$\mathrm{n}=100(\%)$} & \multirow[t]{2}{*}{$\chi^{2}$} & \multirow[t]{2}{*}{$\mathrm{p}$} \\
\hline & & Yes & No & & \\
\hline \multirow[t]{6}{*}{ Willingness to heal } & Years & & & 0.191 & 0.662 \\
\hline & $33-50$ & 6 & 7 & & \\
\hline & $51-75$ & 63 & 24 & & \\
\hline & Gender & & & 0.043 & 0.836 \\
\hline & Men & 15 & 5 & & \\
\hline & Women & 64 & 16 & & \\
\hline \multirow{6}{*}{$\begin{array}{l}\text { If the treatment would cause } \\
\text { a difficult financial situation } \\
\text { for my family, I would not } \\
\text { accept it }\end{array}$} & Years & & & 1.073 & 0.300 \\
\hline & $33-50$ & 16 & 7 & & \\
\hline & $51-75$ & 49 & 28 & & \\
\hline & Gender & & & 6.308 & 0.082 \\
\hline & Men & 17 & 3 & & \\
\hline & Women & 48 & 32 & & \\
\hline \multirow{6}{*}{$\begin{array}{l}\text { The side effects are not } \\
\text { important to me if there will } \\
\text { be a cure }\end{array}$} & Years & & & 1.094 & 0.296 \\
\hline & $33-50$ & 21 & 2 & & \\
\hline & $51-75$ & 70 & 7 & & \\
\hline & Gender & & & 1.578 & 0.208 \\
\hline & Men & 15 & 5 & & \\
\hline & Women & 76 & 4 & & \\
\hline
\end{tabular}

that there was a weak negative statistically insignificant correlation between age $(r=-0.098 ; p=0.428)$, gender $(r=$ $-0.298 ; p=0.325)$, marital status $(r=-0.227 ; p=0.182)$, and evaluations of health-care professionals' communication to patients with malignancies. Respondents who are older

Table 4: Acceptance of family influence on treatment decision making

\begin{tabular}{|c|c|c|c|c|c|}
\hline \multirow[t]{2}{*}{ CCAT - PF } & \multirow[t]{2}{*}{ Variables } & \multicolumn{2}{|c|}{$\mathrm{n}=100(\%)$} & \multirow[t]{2}{*}{$\chi^{2}$} & \multirow[t]{2}{*}{$\mathrm{p}$} \\
\hline & & Yes & No & & \\
\hline Making a decision about & Years & & & 0.071 & 0.790 \\
\hline treatment depends on how & $33-50$ & 2 & 21 & & \\
\hline \multirow{4}{*}{$\begin{array}{l}\text { much my family loves my } \\
\text { doctor }\end{array}$} & $51-75$ & 9 & 68 & & \\
\hline & Gender & & & 2.784 & 0.095 \\
\hline & Men & 0 & 20 & & \\
\hline & Women & 11 & 69 & & \\
\hline It is important for me to & Years & & & 3.653 & 0.056 \\
\hline receive treatment information & $33-50$ & 23 & 0 & & \\
\hline from multiple sources not just & $51-75$ & 73 & 4 & & \\
\hline \multirow{3}{*}{ from my doctor } & Gender & & & 3.068 & 0.080 \\
\hline & Men & 20 & 0 & & \\
\hline & Women & 76 & 4 & & \\
\hline I cannot imagine that all the & Years & & & 9.839 & 0.360 \\
\hline treatments I go through will & $33-50$ & 22 & 1 & & \\
\hline \multirow{4}{*}{ be in vain } & $51-75$ & 76 & 1 & & \\
\hline & Gender & & & 0.963 & 0.326 \\
\hline & Men & 17 & 3 & & \\
\hline & Women & 73 & 7 & & \\
\hline
\end{tabular}

are less likely to rate the communication skills of healthcare professionals compared to younger respondents. In the case of respondents who had a member of the family suffering from malignant diseases, a weak positive statistically significant correlation $(r=0.266 ; p=0.086)$ was observed in relation to the communication score of healthcare professionals $(r=0.266 ; p=0.086)$ (Table 5$)$.

Table 5: Pearson correlation coefficients between measured values of health workers communication score in relation to sociodemographic characteristics

\begin{tabular}{lll}
\hline Variables & \multicolumn{2}{l}{ Strength and direction } \\
\cline { 2 - 3 } & $\mathrm{r}$ & $\mathrm{p}$ \\
\hline Years & -0.098 & 0.428 \\
Gender & -0.298 & 0.325 \\
Marital status & -0.227 & 0.182 \\
Positive family history & 0.266 & 0.086 \\
\hline
\end{tabular}

\section{Discussion}

The study included a total of 100 malignancies, $12 \%$ male and $88 \%$ female. The majority of respondents belonged to the age group over 50 years $(88 \%)$ and in more than half of the respondents $(61 \%)$ the malignant disease was present in the family. In terms of communication between health-care professionals and patients, $51 \%$ were satisfied with the communication, while $49 \%$ of respondents considered the communication inadequate. When it comes to educating health-care professionals about ways to communicate with patients with malignant diseases, research has shown that very few such courses are organized both in our country and abroad. A study conducted in the UK found that nurses and physicians received almost no training in communication and interpersonal dimensions in patient care [7]. This study concluded that approaching the patient who places the patient at the center best describes the most effective way of providing comprehensive care [7], [8] and that learning communication skills can no longer be considered an option but an obligation [9]. A study conducted in America finds that good communication between physicians, nurses with a diseased patient and his or her family is associated with significant care outcomes [10]. Many patients actively seek information and show the importance of obtaining information as a priority. In one of the studies that confirm this, with 12 specific themes mentioned, patients chose information as their greatest need [11]. Compared to our results, as many as $88.9 \%$ of those surveyed confirm that it is important for them to receive information about their illness from multiple sources. A study conducted in the UK showed that patients wanted a belief that someone would look after them, the other part wanted more security and hope; and a number of them expressed an increased need to speak about their concerns and fears and were afraid to discuss it with their family. If we compare the results of the work with the previous study, we can see that our results are similar, because more respondents avoid talking to their family about their illness because they do not want to disturb them. In several studies, it has been shown that seeking information and obtaining it has positive effects on increasing patient satisfaction, improving quality of life, and reducing stress [12]. Patients' need for information may change at different stages of the disease and treatment, one study found that patients with advanced disease wanted less information about their condition [13]. Younger and more educated patients most often take an active role in decision-making that relates to their health [14]. For patients, avoiding conversations about diagnosis can cause feelings of isolation, anxiety, lack of autonomy or control, psychological abandonment, distrust, doubt, and feelings of betrayal [15]. On the other hand, open discussion about diagnosis reduces uncertainty, improves participation in care decisions, provides access to psychological support, encourages self-care, and enables the patient to begin planning for the future [16]. More than half of our respondents were of the opinion that they have a willingness to accept a treatment that brings with it many changes if 
it will prolong their life. Although the overall disclosure of everything related to cancer can have a negative impact on the emotional plan in the short term, most patients tolerate it well over time. Based on our results, we can conclude that there is a very strong correlation with the assessment given by the respondents on the basis of communication with health-care professionals and the care provided during the hospital stay, which shows that they put communication first. Uncertainty is the main cause of emotional distress for patients, if patients do not have fear of insecurity, then this condition is therapeutic in itself and there is relief and hope. The aim of the experts is to improve the quality of life of patients with the prevention of psychological disorders, and to help them to better accept the malignant disease. At the same time, they teach family and friends to be better patient support. Psychological support and assistance are needed not only for those who have just found out about the cancer diagnosis but also for those who are in the recovery phase or have already completed therapeutic procedures, as well as their family members [17]. The patient is the object and subject of treatment and he and the health-care professionals have the same goal; cure as quickly as possible. In the first phase of the patient relationship, it is observed that there are different patients that there are patients who ask and who never ask anything. At the first meeting, health-care professionals can spot different types of patients, and take a stand. Most respondents in our paper are hesitant to talk about side effects during treatment with health-care professionals. Modern medical technique, which is becoming more and more complex every day, significantly helps and largely replaces medical staff. However, overuse of the technique in the absence of real human contact can lead to alienation and dehumanization in these relationships. Problems arise in relation to patient expectations. A study conducted in Latin America found that patients expect to speak with health-care professionals at every contact with a health-care facility. They considered that one of the places for their emotional discharge was related to illness or even financial problems [18]. The presence of clinically relevant levels of psychological distress does not necessarily translate into a patient's desire for referral for treatment, but patients with negative screens may ask for psycho-oncological services [19].

Communication about psychosocial issues is delicate. There is evidence that clinicians do not systematically inquire into the emotional problems of patients, and many clinicians prefer patients to bring up a problem. On the other hand, patients are reluctant to disclose problems [20]. It takes a great deal of skill to respect the advancement of medical science and maintain a humane relationship and holistic approach to patient personality. Diagnosis, treatment, and rehabilitation of a person suffering from a malignant disease are a complex problem area for the patients as well as their social environment. One of the predictors of quality of life is also the dynamics of the family, which are often altered and infrequently disturbed. To the best of our knowledge, this is the first cancer screening study testing hypotheses on reasons for differential non- response empirically. The results of this study confirmed the hypotheses we made in our previous study, using inverse probability weighting to adjust for differential non-response. More importantly, the results of the two other lung cancer screening trials investigating dropout are consistent with ours. Therefore, future cancer screening trials should concurrently assess psychosocial status during the trial to be able to assess the psychosocial effect. The results of our study contribute with evidence of non-response driven by psychosocial status, which in turn may be influenced by the screening intervention itself. The perspectives of patients and clinicians must be aligned in a patient-centered communication process designed to overcome barriers to effective communication. Despite this, no screening tool offers detailed recommendations to guide physician interaction and communication with the patient [21].

\section{Conclusion}

The time devoted to the subjects by the physicians as well as the willingness to listen to the patient is important aspects that influence the adaptation of the disease as well as the treatment. The effectiveness of communication between the patient and the family influences the psychosocial status of the patients with malignant diseases. The family has implications for the decision-making aspects of the patient. We hope to identify routine practices that can lower or eliminate barriers to adequate health care, and better meet patient needs, so we can deploy resources in psychosocial cancer care more efficiently and manage patients better.

\section{Declaration of Patient Consent}

The authors certify that they have obtained all appropriate patient consent forms.

\section{Author's Contribution}

Each author gave substantial contribution to the conception or design of the work and in the acquisition, analysis, and interpretation of data for the 
work. Each author had role in drafting the work and revising it critically for important intellectual content. Each author gave final approval of the version to be published and they agree to be accountable for all aspects of the work in ensuring that questions related to the accuracy or integrity of any part of the work are appropriately investigated and resolved.

\section{References}

1. World Health Organization. WHO Definition of Palliative Care. World Health Organization; 2019. Available from: http://www. who.int/ cancer/palliative/definition/en. [Last accessed on 2019 Jan 01].

2. Subcommittee in Palliative Medicine, Hong Kong College of Physicians. Palliative Care: Setting the Scene for the Future. Hong Kong College of Physicians; 2008. Available from: http:// www.hkcp.org/docs/News/Position paper in Palliative Medicine. pdf. [Last accessed on 2019 Jan 01]. https://doi.org/10.12809/ hkjr1716802

3. Fitch MI. Supportive care framework. Can Oncol Nurs J. 2008;18(1):6-24.

PMid:18512565

4. Dunn J, Adams C, Holland J, Watson M. Reinforcing the role of psycho-social oncology in global cancer prevention: Applying psycho-oncology research in programmes and practice. Psychooncology. 2015;24:1217-21. https://doi.org/10.1002/ pon.3923

5. Tabrizi FJ, Rahmani A, Jafarabadi MA, Jasemi M, Allahbakhshian A. Unmet supportive care needs of Iranian cancer patients and its related factors. J Caring Sci 2016;5:30716. https://doi.org/10.15171/jcs.2016.032 PMid:28032075

6. Siminoff LA, Zyzanski SJ, Rose JH, Zhang AY. The cancer communication assessment tool for patients and families (CCAT-PF): A new measure. Psychooncology. 2008;17(12):1216-24. https://doi.org/10.1002/pon.1350 PMid:18504807

7. Siminoff LA, Graham GC, Gordon NH. Cancer communication patterns and the influence of patient characteristics: Disparities in information-giving and affective behaviors. Patient Educ Couns. 2016;62(3):355-60. https://doi.org/10.1016/j.pec.2006.06.011 PMid: 16860520

8. Gordon HS, Street RL Jr., Sharf BF, Souchek J. Racial differences in doctors information-giving and patients participation. Cancer. 2016;107(6):1313-20. https://doi.org/10.1002/cncr.22122 PMid:16909424

9. Gordon HS, Street RL Jr., Sharf BF, Kelly A, Souchek J. Racial differences in trust and lung cancer patients perceptions of physician communication. J Clin Oncol. 2015;24(6):9-904. https://doi.org/10.1200/jco.2005.03.1955

PMid: 16484700
10. Degner LF, Kristjanson LJ, Bowman D, Sloan JA, Carriere KC O'Neil J, et al. Information needs and decisional preferences in women with breast cancer. JAMA. 2012;277(18):1485-92. https://doi.org/10.1001/jama.1997.03540420081039 PMid:9145723

11. Hietanen $\mathrm{P}$, Aro AR, Holli $\mathrm{K}$, Absetz $\mathrm{P}$. Information and communication in the context of a clinical trial. Eur $J$ Cancer. 2013;36(16):2096-104. https://doi.org/10.1016/ s0959-8049(00)00191-x

PMid: 11044647

12. Schmid-Buchi $S$, Halfens RJ, Muller $M$, Dassen $T$, van den Borne B. Factors associated with supportive care needs of patients under treatment for breast cancer. Eur J Oncol Nurs. 2013;17:22-9. https://doi.org/10.1016/j.ejon.2012.02.003 PMid:22449715

13. Gordon EJ, Daugherty CK. Hitting you over the head: Oncologists disclosure of prognosis to advanced cancer patients. Bioethics. 2013;17(2):142-68. https://doi.org/10.1111/1467-8519.00330 PMid:12812182

14. Maguire P. Improving communication with cancer patients. Eur J Cancer. 2013;35(10):1415-22

PMid:10673972

15. Baile WF, Buckman R, Lenzi R, Glober G, Beale EA, Kudelka AP. A six-step protocol for delivering bad news: Application to the patient with cancer. Oncologist. 2014;5(4):11-302. https://doi. org/10.1634/theoncologist.5-4-302 PMid:10964998

16. Buckman R. Communications and emotions. BMJ 2011;325(7366):672 PMid: 12351345

17. Frankel RM, Stein T. Getting the most out of the clinical encounter: The four habits model. J Med Pract Manage. 2013;16(4):184-91

PMid: 11317576

18. Baker-Glenn EA, Park B, Granger L, Symonds P, Mitchell AJ Desire forpsychological support in cancer patients with depression or distress: Validation of a simple help question. Psychooncology. 2011;20(5):525-31. https://doi.org/10.1002/ pon.1759 PMid:20878852

19. Baker P, Beesley H, Dinwoodie R, Fletcher I, Ablett J, Holcombe $\mathrm{C}$, et al. Youreputting thoughts into my head: $\mathrm{A}$ qualitative study of the readiness of patientswith breast, lung or prostate cancer to address emotional needs through thefirst 18 months after diagnosis. Psychooncology. 2013;22:1402-43. https://doi.org/10.1002/pon.3156 PMid:22890719

20. Epstein R, Street R. Patient-Centered Communication in Cancer Care: Promoting Healing and Reducing Suffering. Bethesda: National Institutes of Health; 2007. https://doi.org/10.1037/ e481972008-001

21. Bultz BD, Groff SL, Fitch M, Blais MC, Howes J, Levy K, et al. Implementingscreening for distress, the $6^{\text {th }}$ vital sign: A Canadian strategy for changingpractice. Psychooncology. 2011;20:463-9. https://doi.org/10.1002/pon.1932

PMid:21456060 